\title{
On the interaction of Linguistic Typology and Functional Grammar
}

\author{
Jan Rijkhoff \\ University of Aarhus
}

Research conducted within the wider theoretical framework of Dik's Functional Grammar has resulted in important contributions to linguistic typology, and, vice versa, empirical facts from a wide variety of languages have significantly improved the theory of Functional Grammar, especially regarding its typological adequacy.

This article discusses the following contributions to Linguistic Typology: the development of a sound sampling methodology, classification of noun categories (Seinsarten), an account of (so-called) number discord, the introduction of the new grammatical category of 'nominal aspect', a new typology of classifiers, and a universal concerning the occurrence of adjectives as a distinct word class. Conversely it will be shown that facts from many different languages have played an important role in the development of a layered model of the noun phrase in Functional Grammar and how currently these facts are used to test hypotheses concerning parallels between NPs and clauses.

\section{Introduction $^{1}$}

An adequate theory of grammar cannot be developed without being exposed to linguistic facts from a wide variety of typologically different languages, and, conversely, empirical research is best guided by theoretical questions. This contribution is concerned with the interaction of systematic empirical research in a wide variety of languages as practiced in the context of linguistic typology and one particular theory, Simon Dik's theory of Functional Grammar.

In my view, the relationship between Functional Grammar and linguistic typology is an excellent example of the fruitful combination of theory-driven data collection and data-driven hypothesis formation. Furthermore, typological facts do not only serve to confirm the theory of Functional Grammar, but they also serve as a heuristics for an extension of the theory. 
I will illustrate the relationship between Dik's theory of Functional Grammar and typology by showing how a research question formulated in the context of Functional Grammar has resulted in several contributions to the field of linguistic typology, and, vice versa, how data that were systematically collected from a wide range of languages have enriched Functional Grammar, thus adding to the typological adequacy of the theory. The research question that I will use for this purpose is one of the questions I have tried to answer in a recent book about noun phrases (Rijkhoff 2002): "Is it possible to construct a layered model of the noun phrase?"

In 1989 Hengeveld proposed a layered model to represent the underlying structure of the clause, which has been very influential but which did not extend to the way noun phrases were analyzed in Functional Grammar. ${ }^{2}$ Below I will demonstrate how the question formulated above, concerning the layered structure of noun phrases, has led to the following contributions to linguistic typology:

a. a sampling method that produces variety samples for exploratory research in linguistic typology (section 2.1)

b. a cross-linguistic classification of nouns that are used to refer to spatial objects (section 2.2)

c. an explanation of certain instances of so-called 'number discord' (section 2.3)

d. the introduction of a new grammatical category 'nominal aspect' (section 2.4)

e. a typology of systems of nominal classification (section 2.5)

f. the formulation of an implicational universal concerning the occurrence of adjectives as a major word class (section 2.6)

I will then show that the typological investigation of noun phrases (NPs) has led to advances in the theory of Functional Grammar (section 3.1) and the formulation of new hypotheses concerning possible semantic and morpho-syntactic parallels between noun phrases and clauses (section 3.2).

\section{From Functional Grammar to Linguistic Typology}

Although the way the various topics are listed in the introduction might suggest a neat division between data collection and theory building, in reality matters tend to be somewhat less structured. Usually theoretical assumptions are 
constantly adjusted to fit new data, and every modification of the theory immediately changes the perspective on the data (old and new). In this sense, the current contribution does not give a true picture of the actual (often more or less chaotic) process of interaction between theory building and data collection. As the late Joseph Greenberg put it (quoted in Croft 2002:5): "You know, you gotta muck around in grammars. You can't just focus on one specific thing and pick it out. You read around and you discover things you never would have thought of."

\subsection{A sampling method for research in Linguistic Typology}

Dik's Functional Grammar differs from most other theories of grammar in its explicit commitment to typological adequacy, i.e. "it should be capable of providing grammars for all languages of any type, while at the same time accounting in a systematic way for the similarities and differences between these languages" (Dik 1997: 14). In other words, the theory should be based on data from a representative sample of the world's languages. Although typologists have worked with language samples for many decades, a suitable method for language sampling was still lacking at the start of the NP project mentioned in the introduction. Since at that time some of my colleagues at the University of Amsterdam (Dik Bakker, Kees Hengeveld, and Peter Kahrel) were also interested in developing a sampling method for exploratory research, we decided to join forces and design such a method ourselves.

The sampling method that we developed is not so much designed to suit statistical or probabilistic purposes, but rather to reveal as much as possible the range of linguistic variation in the languages of the world and we believe that the best way to achieve this is via genetic diversity. To account for linguistic diversity across language families the sampling procedure simply requires that every known family is represented by at least one language. To account for linguistic diversity within families remaining languages must be proportionally distributed over the families on the basis of a factor called Diversity Value. This value can be calculated for every language family (and subfamily) and indicates the linguistic diversity in a family: the greater the linguistic diversity in a family, the higher the Diversity Value and the more languages of that family will be included in the sample. Diversity Values are calculated on the basis of the internal make up of the family, the basic assumption being that the linguistic diversity in a group of genetically related languages correlates with historical 
relations between languages. The more branches a family has close to the top node of the tree, the more diverse it is taken to be.

Table 1 shows how languages are distributed over language families in samples of different sizes; the figure after the family name gives the Diversity Value (DV) of that family (LI = Language Isolate).

Table 1. The distribution of languages over language families in samples of different sizes using Diversity Value (DV).

\begin{tabular}{|c|c|c|c|c|c|c|c|c|c|c|c|c|c|c|c|c|c|}
\hline \multirow{2}{*}{$\frac{\text { Family/DV }}{\text { (Ruhlen 1987) }}$} & \multicolumn{17}{|c|}{ Sample size } \\
\hline & 30 & 40 & 50 & 60 & 70 & 80 & 90 & 100 & 125 & 150 & 175 & 200 & 250 & 300 & 400 & 500 & 1000 \\
\hline Afro-Asiatic/55.53 & 1 & 2 & 2 & 3 & 4 & 5 & 5 & 6 & 8 & 9 & 11 & 12 & 16 & 19 & 26 & 32 & 65 \\
\hline Altaic/14.46 & 1 & 1 & 1 & 1 & 1 & 1 & 2 & 2 & 2 & 3 & 3 & 3 & 4 & 5 & 7 & 9 & 17 \\
\hline Amerind/178.44 & 2 & 5 & 7 & 9 & 12 & 14 & 16 & 18 & 24 & 29 & 35 & 40 & 51 & 61 & 83 & 104 & 209 \\
\hline Australian/67.58 & 1 & 2 & 3 & 4 & 4 & 5 & 6 & 7 & 9 & 11 & 13 & 15 & 19 & 23 & 31 & 39 & 79 \\
\hline Austric/137.41 & 2 & 4 & 5 & 7 & 9 & 11 & 13 & 14 & 19 & 23 & 27 & 31 & 39 & 47 & 64 & 80 & 161 \\
\hline Basque (LI)/1 & 1 & 1 & 1 & 1 & 1 & 1 & 1 & 1 & 1 & 1 & 1 & 1 & 1 & 1 & 1 & 1 & 1 \\
\hline Burushaski (LI)/1 & 1 & 1 & 1 & 1 & 1 & 1 & 1 & 1 & 1 & 1 & 1 & 1 & 1 & 1 & 1 & 1 & 1 \\
\hline Caucasian/8.54 & 1 & 1 & 1 & 1 & 1 & 1 & 1 & 1 & 1 & 2 & 2 & 2 & 3 & 3 & 4 & 5 & 10 \\
\hline Chukchi-Kamchatkan/2.47 & 1 & 1 & 1 & 1 & 1 & 1 & 1 & 1 & 1 & 1 & 1 & 1 & 1 & 1 & 1 & 1 & 3 \\
\hline Elamo-Dravidian/7.43 & 1 & 1 & 1 & 1 & 1 & 1 & 1 & 1 & 1 & 1 & 1 & 2 & 2 & 3 & 3 & 4 & 9 \\
\hline Eskimo-Aleut/3.34 & 1 & 1 & 1 & 1 & 1 & 1 & 1 & 1 & 1 & 1 & 1 & 1 & 1 & 1 & 2 & 2 & 4 \\
\hline Etruscan (LI)/1 & 1 & 1 & 1 & 1 & 1 & 1 & 1 & 1 & 1 & 1 & 1 & 1 & 1 & 1 & 1 & 1 & 1 \\
\hline Gilyak (LI)/1 & 1 & 1 & 1 & 1 & 1 & 1 & 1 & 1 & 1 & 1 & 1 & 1 & 1 & 1 & 1 & 1 & 1 \\
\hline Hurrian (LI)/1 & 1 & 1 & 1 & 1 & 1 & 1 & 1 & 1 & 1 & 1 & 1 & 1 & 1 & 1 & 1 & 1 & 1 \\
\hline Indo-Hittite/39.71 & 1 & 1 & 2 & 2 & 3 & 3 & 4 & 4 & 5 & 7 & 8 & 9 & 11 & 14 & 18 & 23 & 47 \\
\hline Indo-Pacific/123.39 & 2 & 3 & 5 & 7 & 8 & 10 & 11 & 13 & 17 & 20 & 24 & 28 & 35 & 42 & 57 & 72 & 145 \\
\hline Ket $(\mathrm{LI}) / 1$ & 1 & 1 & 1 & 1 & 1 & 1 & 1 & 1 & 1 & 1 & 1 & 1 & 1 & 1 & 1 & 1 & 1 \\
\hline Khoisan/6.97 & 1 & 1 & 1 & 1 & 1 & 1 & 1 & 1 & 1 & 1 & 1 & 2 & 2 & 3 & 3 & 4 & 8 \\
\hline Meroitic (LI)/1 & 1 & 1 & 1 & 1 & 1 & 1 & 1 & 1 & 1 & 1 & 1 & 1 & 1 & 1 & 1 & 1 & 1 \\
\hline Na-Dene/9.44 & 1 & 1 & 1 & 1 & 1 & 1 & 1 & 1 & 1 & 2 & 2 & 2 & 3 & 3 & 4 & 5 & 11 \\
\hline Nahali (LI)/1 & 1 & 1 & 1 & 1 & 1 & 1 & 1 & 1 & 1 & 1 & 1 & 1 & 1 & 1 & 1 & 1 & 1 \\
\hline Niger-Kordofanian/90.38 & 1 & 3 & 4 & 5 & 6 & 7 & 8 & 9 & 12 & 15 & 18 & 20 & 26 & 31 & 42 & 53 & 106 \\
\hline Nilo-Saharan/42.18 & 1 & 1 & 2 & 3 & 3 & 4 & 4 & 5 & 6 & 7 & 8 & 10 & 12 & 15 & 20 & 25 & 50 \\
\hline Pidgins \& Creoles/13.47 & 1 & 1 & 1 & 1 & 1 & 1 & 1 & 2 & 2 & 2 & 3 & 3 & 4 & 5 & 6 & 8 & 16 \\
\hline Sino-Tibetan/38.52 & 1 & 1 & 2 & 2 & 3 & 3 & 4 & 4 & 5 & 6 & 7 & 9 & 11 & 13 & 18 & 22 & 45 \\
\hline Sumerian (LI)/1 & 1 & 1 & 1 & 1 & 1 & 1 & 1 & 1 & 1 & 1 & 1 & 1 & 1 & 1 & 1 & 1 & 1 \\
\hline Uralic-Yukaghir/4.93 & 1 & 1 & 1 & 1 & 1 & 1 & 1 & 1 & 1 & 1 & 1 & 1 & 1 & 2 & 2 & 3 & 6 \\
\hline
\end{tabular}

Diversity Values are also used to distribute languages over subfamilies (and sub-subfamilies etc.); the larger the sample the more internal subgroupings of each family are represented by at least one language. Recursive application of the procedure in a top-down fashion ensures that in the end the genetic distance between individual sample languages is always maximal. This is shown 
in Table 2 for the Amerindian languages (the figures in round brackets after the name of the subfamily indicate: Dv/number of subgroups/number of languages).

Table 2. Representation of the Amerind family and its subfamilies in a 250-language sample.

\begin{tabular}{|c|c|}
\hline Amerind (178.44/6/854) & 51 lgs. \\
\hline Central Amerind (19.05/3/60) & 6 \\
\hline Oto-Manguean (9.17/7/19) & 2 \\
\hline Uto-Aztecan $(11.67 / 8 / 33)$ & 3 \\
\hline Tanoan $(2.88 / 2 / 8)$ & 1 \\
\hline Ge-Pano-Carib (29.25/5/77) & 9 \\
\hline Macro-Carib (13.29/5/77) & 3 \\
\hline Ge-Pano $(22.35 / 2 / 116)$ & 6 \\
\hline Macro-Panoan $(12.72 / 6 / 72)$ & 3 \\
\hline Macro-Ge $(16.38 / 14 / 44)$ & 3 \\
\hline Northern Amerind (45.48/3/232) & 14 \\
\hline Hokan $(17.20 / 8 / 43)$ & 4 \\
\hline Penutian $(21.46 / 8 / 92)$ & 6 \\
\hline Almosan-Keresiouan (15.98/2/97) & 4 \\
\hline Almosan (10.08/3/62) & 2 \\
\hline Keresiouan $(10.13 / 4 / 35)$ & 2 \\
\hline Equatorial-Tucanoan (44.96/2/268) & 14 \\
\hline Macro-Tucanoan $(24.21 / 19 / 59)$ & 6 \\
\hline Equatorial $(30.89 / 12 / 209)$ & 8 \\
\hline Chibchan-Paezan $(16.91 / 2 / 71)$ & 5 \\
\hline Chibchan $(10.89 / 7 / 39)$ & 2 \\
\hline Paezan $(11.67 / 10 / 32)$ & 3 \\
\hline Andean $(9.50 / 6 / 30)$ & 3 \\
\hline
\end{tabular}

In this case I have used Ruhlen's classification of languages, but our method also works with other classifications, such as the one proposed by Voegelin and Voegelin (1977) and the one that is used in the Ethnologue (e.g. Grimes 1997). The sampling method is now part of a larger computer program that also allows the researcher to experiment with samples of different sizes to see how languages are going to be distributed and to what extent certain families and areas will be covered. In fact, one can make many different kinds of adjustments; for example, whether or not to include VSO languages, European languages, or Pidgin \& Creole languages (for a detailed description of our sampling method and a discussion of other sampling procedures, see Rijkhoff et al. (1993) and Rijkhoff and Bakker (1998)). 
2.2 A cross-linguistic classification of nouns that are used to refer to spatial objects

Obviously, nouns occupy a central place in a study of the structure of NPs. An examination of nouns in a 52-language sample constructed according to the method sketched in Section 2.1 above revealed that first order nouns, i.e. nouns that are used to refer to spatial entities, can be defined in terms of two features: Shape and Homogeneity (Rijkhoff 1991, 2002). As far as I am aware, this is the first attempt of its kind to come up with a cross-linguistic classification of nouns and it can be directly attributed to the fact that in FG, as opposed to many other theories of grammar, linguistic structures are represented as semantic rather than syntactic entities (Dik 1997:8).

Table 3. Classification of nouns (or: SeInSARten - cf. AKtionsarten in verb semantics)

\begin{tabular}{|c|c|c|}
\hline Space & -Homogeneity & +Homogeneity \\
\hline \multirow[t]{2}{*}{-Shape } & \multicolumn{2}{|c|}{ general noun } \\
\hline & sort noun & mass noun \\
\hline \multirow[t]{2}{*}{ +Shape } & \multicolumn{2}{|c|}{ set noun } \\
\hline & singular object noun & collective noun \\
\hline
\end{tabular}

If a noun has a positive value for the lexical feature Shape (SET NOUn, SINGULAR OBJECT NOUN, COLLECTIVE NOUN), this means that the nominal property is characterized as having a definite outline in the spatial dimension. It also means that SET NOUNS, SINGULAR OBJECT NOUNS, and COLLECTIVE NOUNS can be in a direct construction with a numeral (only discrete entities can be counted). Nouns with a negative value for the feature Shape (GENERAL NOUNS, SORT NOUNS and MASS NOUNS), on the other hand, cannot be in a direct construction with a numeral; they require a so-called classifier of some kind, which functions as a kind of 'individualizer' (Lyons 1977:462, see also section 2.5).

Nouns with a positive value for the lexical feature Homogeneity (MAss NOUNS, COLLECTIVE NOUNS) designate a property that is characterized as being agglomerative (e.g. water added to water is still 'water'). In other words, the referent of an NP headed by a noun that designates a homogeneous property consists of portions (in the case of a mass noun such as 'water') or members (in the case of a collective noun such as 'family'). General nouns and set nouns are neutral with respect to the feature Homogeneity. Thus: ${ }^{3}$ 
- a general noun (-Shape) designates a property that is only characterized as not having a definite outline

- a sort noun (-Shape, -Homogeneity) designates a property that is characterized as not having a definite outline and as being non-agglomerative

- a mass noun (-Shape, +Homogeneity) designates a property that is characterized as not having a definite outline and as being agglomerative

- a set noun (+Shape) designates a property that is only characterized as having a definite outline

- a singular object noun (+Shape, -Homogeneity) designates a property that is characterized as having a definite outline and as being non-agglomerative

- a collective noun (+Shape, + Homogeneity) designates a property that is characterized as having a definite outline and as being agglomerative

Below are examples of each nominal subcategory.

Dutch: singular object noun or 'count noun' [+Shape, -Homogeneity]

(1) twee boek-en [numeral+noun+plural]

two book-PL

'two books'

Dutch: collective noun [+Shape, + Homogeneity]

(2) twee familie-s [numeral+noun+plural]

two family-PL

'two families'

Set nouns are like singular object nouns and collective nouns in that they can be modified directly by a cardinal numeral, i.e. they do not require the appearance of a classifier. However, set nouns differ from the two other [+Shape] nominal subcategories in that they are transnumeral (Andrzejewski 1960:71):

The vast majority of [Oromo nouns] are associated with neither plurality nor singularity, i.e. the forms themselves give us no information as to whether what is denoted by them is one or more than one. When such forms are used, only the context can provide us with information about the number of what is denoted.

Oromo (Stroomer 1987:59): set noun [+Shape]

(3) gaala lamaani [noun+numeral; no plural] camel(s) two 'two camels'

Mass nouns, sort noun, and general nouns, on the other hand, all require some kind of classifier when they are modified by a numeral. Mensural classifiers 
typically occur with mass nouns and specify the size, weight, or volume of the referent of the NP.

Dutch: mass noun [-Shape, + Homogeneity]

(4) een pond kaas [numeral+mensural classifier+noun]

a pound cheese

'a pound of cheese'

The meaning of a sort noun does not seem to include the notion of spatial boundedness or discreteness either. According to Hundius and Kölver (1983: 166, 181-182) Thai nouns (which are categorized as 'sort nouns' in Table 3 because they occur with sortal or numeral classifiers):

[...] purely denote concepts and, for this reason, are incompatible with direct quantification.

[...], Thai nouns do not in themselves contain any numerical or referential indications. [..] they are purely conceptual labels which, in order to be appropriately related to objects of the non-linguistic world, always and in principle stand in need of interpretation which has to be inferred from both linguistic and non-linguistic context.

Thai (Hundius and Kölver 1983: 172): sort noun [-Shape, -Homogeneity]

(5) rôm săam khan [noun+numeral+sortal classifier]

umbrella three CLF:long, handled object

'three umbrellas'

But whereas Thai distinguishes between mensural and sortal classifiers (i.e. between mass nouns and sort nouns), such a distinction is deemed to be absent in the case of Yucatec Maya (hence I have labeled classifiers of the Yucatec variety 'general classifiers' and the nouns that combine with these classifiers 'general nouns'); cf. Lucy (1992:74):

Outside of the restriction on compatibility with other classifiers, little in the grammar of Yucatec appears to hinge on, or correlate with, this "sortal" [...] versus "mensural" distinction, and it is difficult to know what status it should be given.

Yucatec Maya (Lucy 1992:74): general noun [-Shape] a/one-CLF banana [numeral+general classifier+noun]

(6) a. 'un-tz'iit há'as 'one/a 1-dimensional banana (i.e. the fruit)'

b. 'un-wáal há'as 'one/a 2-dimensional banana (i.e. the leaf)'

c. 'un-kúul há'as 'one/a planted banana (i.e. the plant/tree)' 

d. 'un-kúuch há'as
'one/a load banana (i.e. the bunch)'
e. 'um-p'iit há'as
'one bit banana (i.e. a bit of the fruit)'

It appears that cross-linguistically members of the following four nominal subcategories are used to refer to a single, discrete, spatial object in the real world such as 'dog' or 'knife' (Rijkhoff 2002: Chapter 2; see also note 3):

1. singular object nouns: the noun is in a direct construction with the numeral; plural marking is obligatory, both with and without a numeral;

2. set nouns: the noun is in a direct construction with the numeral; so-called number marking (if available at all) is absent when the noun is modified by a numeral;

3. sort nouns: the noun is not in a direct construction with the numeral; instead the numeral combines with a sortal (or numeral) classifier and number marking is absent, both with and without a numeral;

4. general nouns: the noun is not in a direct construction with the numeral; instead the numeral combines with a general classifier and number marking is absent, both with and without a numeral.

A language may employ more than one nominal subcategory to refer to single, discrete spatial objects. For example, Ngiti uses singular objects nouns to refer to human entities and set nouns for nonhuman objects (Kutsch Lojenga 1994:340, 355), and Mandarin Chinese, which has sort nouns, appears to be in the process of developing a new category of set nouns to refer to humans (Norman 1988: 159; Rijkhoff 2002:37,153-154).

The classification of nominal subcategories (Table 3 ) is interesting for a number of reasons. First of all it tells us something about the different kinds of nouns that are used in the world's languages to refer to spatial objects and at some point we need to explain this kind of variation. Another reason that makes this classification of nouns interesting has to do with possible parallels between NPs and clauses (section 3.1).

\subsection{An explanation of so-called 'number discord' in languages across the globe}

This contribution of FG to linguistic typology is mainly due to the establishment of set nouns as a distinct type of noun (see section 2.2) and to Dik's insistence to take languages seriously (Dik 1997:18; see also section 2.4 below): "Whenever there is some overt difference between two constructions X and Y, start out on the assumption that this difference has some kind of functionality in the system". 
In quite a few languages we find 'number discord' between the subject NP and the agreement marker in the verbal complex, as in the examples from Georgian, Lango, and Oromo:

Georgian (Harris 1981:22)

(7) sami ḳnuṭi goravs

three kitten roll:3sG

'three kittens are rolling'

Lango (Noonan 1992:168)

(8) gúlú àdêk òtò̀

pot three 3sG:die:PERF

'three pots broke'

Oromo (Stroomer 1987:107)

(9) gaala lamaani sookoo d'ak'-e

camel two market go-3sg.M.past

'Two camels went to the market'

In each case we see that there is 'number discord' between the plural subject and the verb, which is inflected for the singular. This phenomenon has been observed in quite a few languages and is sometimes attributed to sloppy number marking on the part of the speaker (cf. Mithun 1988:212). However, in my sample systematic, compulsory number discord of this kind is only attested in languages with what I have called 'set nouns' in the classification of nouns in Table 3. Recall that set nouns are TRANSNUMERAL NOUns that can be directly modified by a cardinal numeral (as in quasi-English: 'two house'). As the name indicates, the unmarked form of the noun designates a set, which may contain any number of members, including 'one'. Hence set nouns can be translated into English as nouns with singular or plural number (see the quotation from Stroomer's book on Oromo above).

I have argued that in the languages with set nouns the pronominal element in the verbal complex agrees with the set rather than with the number of individuals in the set (Rijkhoff 1993). If this is correct, we are not dealing with 'number discord' at all. Since agreement is with the set, which is always a singular entity (regardless of the number of members it contains), we would actually expect singular agreement in the verb.

There is reason to believe, however, that the so-called number marker that may appear on set nouns in certain languages is not a number marker at all. This brings us to another contribution to linguistic typology due to the NP 
project that was implemented in the context of FG: the new grammatical category of 'nominal aspect'.

\subsection{Nominal aspect}

When we compare Dutch and Oromo, both of which are deemed to have number markers, we find that there are some significant differences between the two languages: ${ }^{4}$

- singular object noun vs. set noun

In Dutch the unmarked noun denotes a singular object: paard $=1$ horse In Oromo the unmarked noun denotes one or more objects (i.e. a set): farda = horse(s)

- obligatory vs. optional plural marking

In Dutch the plural marker is obligatory without a numeral: paard-en = horse-PL.

In Oromo the so-called plural marker is optional: farda/fardoollee $=$ horses.

- modification by cardinal numeral: presence vs. absence of plural marker

In Dutch the plural marker is obligatory with a numeral: 2 paard-en '2 horse-PL'.

In Oromo the so-called plural marker must be absent with a numeral: farda 2 (cf. ${ }^{\star}$ fardoollee 2 ).

- use of singular number marker:

Oromo has an overt marker for singular number: harree $=\operatorname{donkey}(s)$, harreettii $=\mathrm{a} /$ the (female) donkey.

Dutch does not (overtly) mark singular number: ezel $=1$ donkey.

If both Dutch and Oromo have number marking, then how can we explain these differences? Let us assume that Dutch has a true plural marker, in that the plural suffix must be used whenever the referent involves more than one object. In Oromo, on the other hand, the so-called number marker is optionally used by the speaker to indicate whether we are dealing with a SINGLETON SET or a NON-SINGLETON (COLLECTIVE) SET. Since this marker specifies what kind of set the speaker refers to I have argued we are dealing with a qualitative distinction in the case or Oromo (as opposed to a quantitative distinction, as in Dutch). Consequently I have proposed to call the so-called number marker on set nouns 
in Oromo and many other languages a NOMINAL ASPECT MARKer (Rijkhoff 1991; 2002).

Aspectuality is concerned with the way a property or relation is represented in some dimension. Verbal ASPECT has to do with the way a verbal property or relation is represented in the temporal dimension. NominAL ASPECT relates to the way a nominal property is represented in the spatial dimension. The socalled number marker on set nouns in Oromo and many other languages has to do with the way the nominal property designated by the set noun is represented in space: as a singleton set or as a collective set. I will return to nominal aspect below where it will also become clear that the discovery of 'nominal aspect' as a new grammatical category is mostly due to

- the hypothesis that NPs can be analyzed as layered structures in which nominal attributes (such as articles, demonstratives, numerals, adjectives, etc.) are organized in various, hierarchically organized layers of modification (section 3.1; for a preview see Figure 1 in the next section), and

- the hypothesis that NPs and clauses can be analyzed in a similar fashion (section 3.2).

\subsection{A typology of classifiers}

Classifiers are typically attested in languages in which nouns are semantically underspecified or "very vague in their reference" (Foley 1997:232, see also Bisang 1996:519). They can be defined as elements that ascribe "discoursally relevant properties to the otherwise semantically vague noun” (Foley 1997:245). Classifiers are a notoriously problematic category and consequently there have been quite a few attempts to come up with some kind of typology. In this area, too, the theory of Functional Grammar appears to have been more successful than other theories of grammar.

Recently Grinevald (2000) has proposed a morpho-syntactic typology of classifiers that is based on (an earlier version of) the layered NP model to be discussed in Section 3 below. Her typology includes the three main types of classifier: noun classifier, numeral classifier, and genitive classifier.

Noun classifier — Jakaltek (Grinevald 2000:65)

(10) kaj te7 tahnaj ixpij

red $\operatorname{CLF}$ (plant) ripe tomato

'The ripe (plant) tomato is red' 
Numeral (or sortal) classifier - Mandarin Chinese (Grinevald 2000:63)

(11) san-ge ren

three-CLF person

'three people'

Genitive classifier - Ponapean (Grinevald 2000:66)

(12)
a. kene-I
mwnge
CLF(edible)-GEN:1 food
'my food'

b. were-i pwoht

CLF(transport)-GEN:1 boat

'my boat'

Grinevald (2000:77) argues that these major types of classifiers can be conceived of as "different operators which correspond to different modes of individuation manifested by their different semantics".

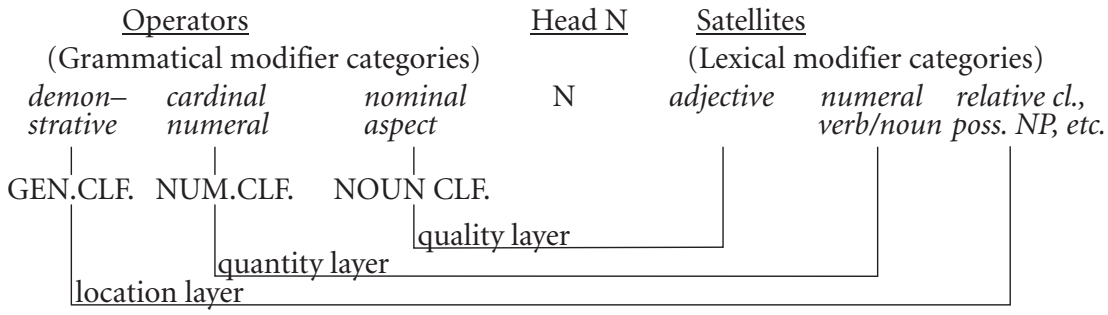

Figure 1. A layered approach to classifiers (cf. Grinevald 2000:76-79).

As shown in Figure 1, each classifier type appears in a different layer of this simplified version of the underlying structure of the noun phrase (see also note 7). In Grinevald's view noun classifiers must be associated with the qualitative layer of modification, which has to do with inherent, typical properties of the referent. Not surprisingly, she places numeral/sortal classifiers in the quantity layer of modification; genitive classifiers appear in the location layer (cognitively Location and Possession are closely related concepts; cf. Lyons 1967; Christie 1970; Clark 1978; Heine 1997); for more details I refer to Grinevald (2000) and Craig (1992). 
2.6 An implicational universal concerning the occurrence of adjectives as a major word class

Not every language has a distinct class of adjectives. Languages without adjectives typically employ qualifying NPs (headed by an abstract noun) or relative clauses (headed by a stative or descriptive verb) to express adjectival notions, as in the English paraphrases 'the man with richness' or 'the man who riches / who is rich'. Compare the following examples from Galela and Hausa:

Galela (van Baarda 1908:35f): verbal strategy

awi dòhu i lalamo

his foot it be.big:PRT

'his big foot'

Hausa (Schachter 1985:15): nominal strategy

(14) mutum mai alheri / arzaki / hankali

person having kindness / prosperity / intelligence

'a kind/prosperous/intelligent person'

Table 4 shows that in my sample nearly all languages that employ numeral (or sortal) classifiers, i.e. Burmese, Gilyak, Korean, Mandarin, Nung, and Vietnamese (the names are in small caps in Table 4), belong to the group of languages without a major, distinct class of adjectives. Hmong Njua is the only classifier language with adjectives. Note that Table 4 does not include the four languages in my sample with so-called 'flexible' or 'multifunctional' lexemes, i.e. Samoan, Imbabura Quechua, Hurrian, and Turkish (see Rijkhoff (2000; 2002:14-16, 141-145) for discussion).

This is, for example, what Li and Thompson (1989:826-827) say about 'adjectives' in Mandarin Chinese:

Strictly speaking, there is no class of words in Chinese that we can call 'adjective. That is, while there are certainly words which denote qualities or properties of entities, from a grammatical point of view it is difficult to distinguish 'adjectives' from 'verbs'. First, in Chinese, words denoting qualities and properties do not occur with a copula as they do in Indo-European languages. [...]. Secondly, quality and property words in Chinese are negated by the same particle bù as are verbs: [...]. Thirdly, when an 'adjective' modifies a noun, it occurs with the same nominalising particle de as verb phrases do: [...]. For these reasons, it is sensible to consider quality and property words in Chinese simply as a subclass of verbs, one which we might call 'adjectival verbs'. 
Table 4. Classifiers and languages with and without a major, distinct class of adjectives.

\begin{tabular}{|c|c|}
\hline $\begin{array}{l}\text { Languages with a } \\
\text { major, distinct class } \\
\text { of adjectives } \\
(\mathrm{N}=+ \text { Shape }) \\
\text { [22 lgs.] }\end{array}$ & $\begin{array}{l}\text { Abkhaz, Alamblak, Basque, Berbice Dutch Creole, } \\
\text { Bukiyip (=Mountain Arapesh), Burushaski, Dutch, } \\
\text { Georgian, Guaraní, Hittite(?), HмoNG NJuA, } \\
\text { Hungarian, Ika, Kayardild, Ket, Nama Hottentot, } \\
\text { Nasioi, Ngalakan, Ngiti, Oromo, Sumerian, Wambon. }\end{array}$ \\
\hline $\begin{array}{l}\text { Languages without a } \\
\text { major, distinct class } \\
\text { of adjectives } \\
(\mathrm{N}=+ \text { Shape or }- \text { Shape }) \\
\text { [23 lgs.] }\end{array}$ & $\begin{array}{l}\text { Babungo, Bambara, Burmese, Chukchi, Galela, } \\
\text { Gilyak (=Nivkh), Gude, Hixkaryana, Kisi, Koasati, } \\
\text { Korean, Krongo, Lango, Mandarin Chinese, Nung, } \\
\text { Nunggubuyu, Pipil, Sarcee, Tamil, Tsou, } \\
\text { Vietnamese, West Greenlandic, Cayuga(?). }\end{array}$ \\
\hline Unknown: [3 lgs.] & Etruscan, Meroitic, Nahali. \\
\hline
\end{tabular}

More or less the same holds for the other classifier languages in the sample, which all use verbs to express adjectival notions (Rijkhoff 2000:224-227). This is, however, not the case in Hmong Njua, the only classifier language that has a class of adjectives. There is a clear difference between modifying verbs and adjectives in this language in that the former need to be part of a relative clause introduced by the relative pronoun $k w s$ whereas adjectives do not appear with such a conjunction; compare for example (17) and (18):

Hmong Njua (Harriehausen 1990: 144, 141)

(15) ob phau ntawn loj nua

two CLF book big DEM

'these two big books'

(16) tug miv tub kws ua si miv

CLF boy RCM play small

'the playing boy (or: the boy who is playing) is small'

Recall that the employment of numeral/sortal classifiers usually indicates that the language in question uses -Shape nouns for discrete spatial objects in the external world (Table 3). This suggests that there is a relationship between lexical noun semantics and the occurrence of adjectives as a major word class in a language. Languages with classifiers (i.e. languages using -Shape nouns for discrete spatial objects) typically lack a class of adjectives and, conversely, nearly all languages with adjectives use SINGULAR OBJECT NOUNS or SET NOUNS (both +Shape) to refer to discrete spatial objects (see section 2.2). Hmong Njua seems to be the only exception, since it has both adjectives (which are almost exclusively attested in languages with + Shape nouns in Table 4) and classifiers (which are 
mainly restricted to languages with -Shape nouns in Table 4). However, it appears that in Hmong Njua classifiers have developed into number markers, or perhaps I should rather say NOMINAL ASPECT MARKERS, since the grammaticalized classifiers in Hmong Njua may indicate 'singularity' or 'collectivity'. Recall that set nouns are transnumeral and they are the only type of nominal that can occur with a singulative or a collective aspect marker.

Hmong Njua (Harriehausen 1990: 100)

ob tug naab

two CLF snake

'two snakes'
a. tsev
'house(s)'
$(\mathrm{N}=$ transnumeral $)$
b. lub tsev
'the house'
(singulative)
c. cov tsev
'(the) houses'
$(\text { collective })^{5}$

If it is true that Hmong Njua does not use sort NOUns (with the feature -Shape) for discrete spatial entities such as 'house' or 'umbrella', which is what one would expect in a classifier language, but SET NOUNs (with the feature +Shape), we can formulate the following implicational universal (recall that I am only referring to nouns that are used to refer to concrete, spatial objects; see Rijkhoff 2000 for more details):

If a language has a major, distinct class of adjectives, then the nouns in that language are generally specified as [+Shape], which means that the properties that are designated by these nouns are characterized as having a spatial boundary.

In other words, it seems to be a necessary (though not a sufficient) condition for a language to employ set nouns and/or singular object nouns to refer to discrete spatial objects such as 'knife' or 'table', before it can have a major, distinct class of adjectives. 


\subsection{Summing up}

To sum up: a cross-linguistic investigation of noun phrases in the theoretical context of FG has resulted in the following contributions to Linguistic Typology:

- a sampling method for typological research

- a cross-linguistic classification of nouns (see also below on Seinsarten)

- an explanation of so-called 'number discord'

- the discovery of a new grammatical category 'nominal aspect'

- a typology of systems of nominal classification

- an implicational universal concerning the occurrence of adjectives as a major, distinct word class

These contributions can be seen as the direct consequence of three features that are characteristic of FG:

- the requirement that FG must be typologically adequate

- the emphasis on semantics (rather than syntax) in the FG model of representation

- the layered approach to clause structure in FG, which served as a major source of inspiration for the analysis of noun phrase structure

One could ask if the same result could have been achieved with another theory of grammar. This is a legitimate question, since some of the features listed above are also characteristic of other theories of grammar (e.g. layering in Role and Reference Grammar; Van Valin and LaPolla 1997). I would like to contend, however, that it is both the combination of the three features mentioned above and the significance that is attributed to each of these features in the overall FG framework which gave rise to this particular set of contributions to Linguistic Typology. Therefore I believe it is rather unlikely that someone working with another theory of grammar would have come up with the results discussed in sections 2.1-2.6.

\section{From Linguistic Typology to Functional Grammar}

I mentioned in the introduction that the relationship between FG and typology is an excellent example of the fruitful combination of theory driven data collection and data driven hypothesis formation, and that typological facts do not only serve to confirm the theory of FG, but also as a heuristics for an extension of the theory. 
So far I have mainly been concerned with theory-driven data collection. This section focuses on the impact of typological data on FG. First I will demonstrate how typological facts made it possible to construct a layered model of the noun phrase (section 3.1). Then I will show how typological research has been used to formulate hypotheses concerning possible semantic and morphosyntactic parallels between the noun phrase and the clause (section 3.2).

\subsection{A layered model of the noun phrase in Functional Grammar}

The typological data that were collected during the NP project played an essential role in the attempt to construct a layered model of the noun phrase. But before we continue it may be useful to point that the layered NP model that I have proposed differs in some important ways from the 'standard' NP structure as presented in Dik (1997). In Dik's book, NPs are represented according to the general schema (Dik 1997: 132):

$$
\left(\omega \mathrm{x}_{\mathrm{i}}: \varphi_{1}\left(\mathrm{x}_{\mathrm{i}}\right): \varphi_{2}\left(\mathrm{x}_{\mathrm{i}}\right): \ldots: \varphi_{\mathrm{n}}\left(\mathrm{x}_{\mathrm{i}}\right)\right)[\mathrm{n} \geq 1]
$$

where

- $\quad \omega$ stands for various kinds of grammatical categories (or: 'term operators') such as '(in)definiteness', 'singular/plural number' or 'cardinal number'

- $\mathrm{x}_{\mathrm{i}}$ is the term (NP) variable, "ranging over the set of potential referents of the term", and

- $\varphi_{1} \ldots \varphi_{\mathrm{n}}$ signify lexical elements ('predicates') such as nouns, adjectives or verbs; they are also called 'restrictors', because they successively restrict the range of possible referents of the NP. The first restrictor $\left(\varphi_{1}\right)$ is normally the head noun; other restrictors can take a variety of forms (e.g. adjective, possessor phrase, relative clause)

For example, the structure

(20) $\left(\mathrm{d} 3 \mathrm{x}_{\mathrm{i}}: \operatorname{dog}_{\mathrm{N}}\left(\mathrm{x}_{\mathrm{i}}\right): \operatorname{black}_{\mathrm{A}}\left(\mathrm{x}_{\mathrm{i}}\right)\right)$ 'the three black dogs'

is to be paraphrased as "definite three entities $\mathrm{x}_{\mathrm{i}}$ such that the nominal property "dog" applies to $\mathrm{x}_{\mathrm{i}}$, such that the adjectival property "black" applies to $\mathrm{x}_{\mathrm{i}}$.

There are two main differences between the 'standard' NP structure presented in Dik (1997) and the 'layered' NP model that I have proposed, a simplified version of which is given in (21) (see Figure 2 below to get an impression as to the modifier categories that could fill the various slots; I refer to Rijkhoff (2002) for an elaborate presentation of the layered NP model). 


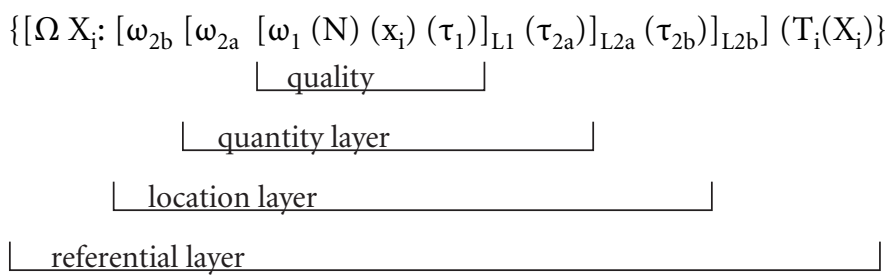

Since this is a general structure that is designed to accommodate NPs in any natural language, certain modifier slots may remain empty. For example, not every language employs nominal aspect markers (symbolized by $\omega_{1}$ ).

$\Omega=$ discourse operator (symbolizes grammatical categories such as (in)definiteness or (non-)specificness); this operator has the widest scope and is concerned with discourse properties of the referent

$\mathrm{X}=$ referent variable (symbolizes the referent of the NP)

$\mathrm{T}=$ discourse satellite (symbolizes lexical modifiers specifying discourse properties of the referent); the $\mathrm{T}$ satellite functions as a predicate that takes the referent of the NP (symbolized by $\mathrm{X}_{\mathrm{i}}$ ) as its argument

$\omega=\mathrm{NP}$ operator (symbolizes descriptive grammatical modifier categories); quality operator $\omega_{1}$ (nominal aspect) has the nominal predicate in its scope; quantity operator $\omega_{2 \mathrm{a}}$ (number, cardinality) has in its scope the quality layer $\mathrm{L}_{1}$; location operator $\omega_{2 \mathrm{~b}}$ (demonstrative) has in its scope the quantity layer $\mathrm{L}_{2 \mathrm{a}}$

$\mathrm{N}=$ (head) noun

$\mathrm{x}=\mathrm{NP}$ or term variable (symbolizes the descriptive content of the NP, the information that the speaker uses to describe the referent of the NP in terms of the notions Quality, Quantity, and Location)

$\tau=\mathrm{NP}$ or term satellite (symbolizes descriptive lexical modifier categories, such as adjective, possessor NP, relative clause); a $\tau$ satellite is a predicate that takes the NP variable $\mathrm{x}_{\mathrm{i}}$ as its argument (this is not indicated in (21)); I have also omitted the predicate variable $\mathrm{f}$ in this representation)

First, there is of course the layered organization of my NP model, reflecting the scope differences of the various kinds of grammatical and lexical modifier categories (this is demonstrated in more detail in Rijkhoff 2002: Chapter 7). In this model the noun and its lexical modifiers are no longer regarded as 'restrictors'. Instead the noun is regarded as the head of the phrase and the other lexical constituents, symbolized by $\tau$ (modifiers such as: adjective, genitive, 
relative clause), as satellites of the noun - just like adverbs and adverbials are treated as satellites of the verb at the level of the clause.

Another important difference concerns the distinction between the descriptive function of an NP and the referential function of an NP. The main reason to distinguish between these functions in the layered NP model is to bring out more clearly the dual function of the NP. On the one hand NPs give a "physical" description of a referent regarding its qualitative ("how"), quantitative ("how many"), and positional ("where") properties. This descriptive aspect of the NP is symbolized by the x-variable. On the other hand, NPs are also referring expressions: the referent of an NP is an entity that is talked about and figures in the world of discourse. This constitutes the referential side of the $\mathrm{NP}$ and is symbolized by the X-variable in the layered NP model. ${ }^{6}$ The presence of both a variable that symbolizes the descriptive content of the NP and a variable that symbolizes the referent of that NP makes it possible to explain

a. that different NPs or 'descriptions' (symbolized by $x_{i}$ and $x_{j}$ below) can be used to refer to the same entity (symbolized by $\mathrm{X}_{\mathrm{i}}$ ), as in:

(22) The Morning $\operatorname{Star}\left(\mathrm{X}_{\mathrm{i}}, \mathrm{x}_{\mathrm{i}}\right)$ is the Evening $\operatorname{Star}\left(\mathrm{X}_{\mathrm{i}}, \mathrm{X}_{\mathrm{j}}\right)$.

b. that anaphoric reference can be made to the referent $\left(\mathrm{X}_{\mathrm{i}}\right)$ and to a particular description of that referent $\left(\mathrm{x}_{\mathrm{i}}\right)$, as in $(\mathrm{A}=$ anaphoric reference):

(23) A: My neighbor $\left(\mathrm{X}_{\mathrm{i}}, \mathrm{x}_{\mathrm{i}}\right)$ just saw a black cat and now the superstitious old fool $\left(\mathrm{X}_{\mathrm{i}}, \mathrm{X}_{\mathrm{j}}\right)$ believes he $\left(\mathrm{A} \mathrm{X}_{\mathrm{i}}\right)$ is in for some bad luck today.

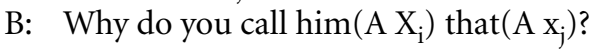

It is important to emphasize that it would have been impossible to fill all the slots in the layered model of the noun phrase without some of the data that were collected in the typological part of the NP project. This holds in particular for nominal aspect markers $\left(\omega_{1}\right)$ and lexical expressions of cardinality $\left(\tau_{2 \mathrm{a}}\right.$ in the model above), i.e. numeral nouns and verbs, which can only be found in a sample that includes languages from many different types, families and geographic areas (but see note 9).

\subsection{New hypotheses: parallels between the noun phrase and the clause}

I argued in section 3.1 that the some of the data that were collected in the typological part of NP project played a crucial rule in the construction of a layered model of the noun phrase. In this section I will show that typological data were also essential in the formulation of new hypotheses, concerning 
possible parallels between NP structure and clause structure (at least that part of the clause that is called 'extended predication' in Functional Grammar, and which more or less corresponds to the ideational metafunction in Halliday's Systemic Functional Grammar; cf. Hengeveld 1990 and Dik 1997: Chapter 12). These data suggest that NPs and clauses can be analyzed in the same fashion, i.e. as structures that consist of three hierarchically organized DESCRIPTIVE LAYERS (accommodating grammatical and lexical modifiers that specify qualitative, quantitative, and locative properties of the referent) and an all-encompassing REFERENTIAL LAYER (providing slots for grammatical and lexical modifiers that specify discourse properties of the referent; see (21) above).

Let us first focus on the descriptive modifier categories. Figure 2 shows how the same descriptive layers can be used for the analysis of NPs and clauses (or rather 'extended predications'). ${ }^{7}$ $\begin{array}{lr}\text { Grammatical expression of Quality }(\pi 1) & \text { Lexical expression of Quality }(\sigma 1), \\ \text { Quantity }(\pi 2 \mathrm{a}) \text {, and Location }(\pi 2 \mathrm{~b}) & \text { Quantity }(\sigma 2 \mathrm{a}), \begin{array}{r}\text { and Location }(\sigma 2 \mathrm{~b}) \\ \text { in the clause. }\end{array}\end{array}$

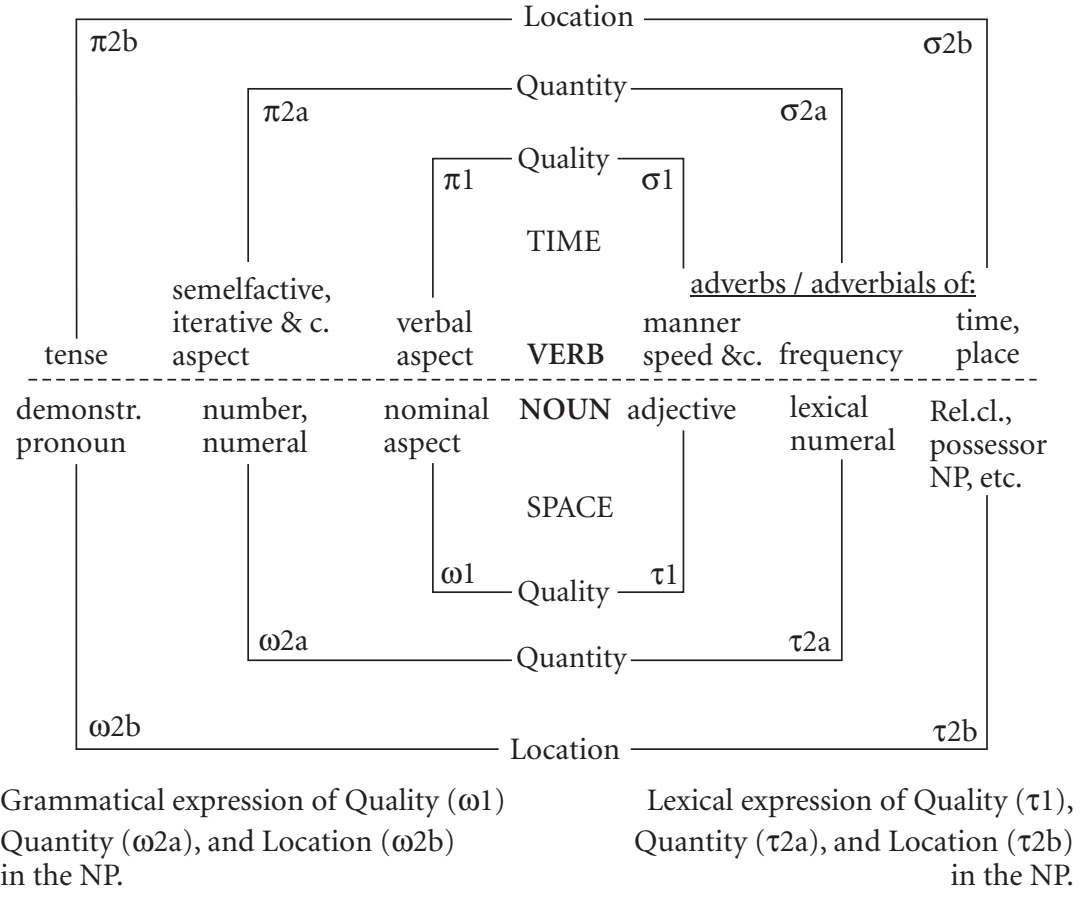

Figure 2. Symmetry in (the descriptive part of) the underlying structure of NPs and clauses. 
Thus, 'tense' in the clause (temporal deixis, localization in time) corresponds to 'demonstrative pronoun' in the NP (spatial deixis, localization in space). Similarly, iterative aspect in the clause corresponds to number/ cardinality in the NP: one specifies the number of events (temporal entities), the other the number of objects (spatial entities) — and so on. In sum, at some level of abstraction we find the same descriptive grammatical and lexical modifier categories: qualitative modifiers, quantitative modifiers and locative modifiers.

Similar things can be said about modifiers at the referential level, relating to discourse properties of the referent of the NP and to discourse properties of the referent of the predication. Figure 3 shows that the Discourse operators 'definite'/'indefinite' and 'actual'/'non-actual' both relate to the OCCURRENCE of the referent (object or event) in the world of discourse.

\begin{tabular}{lll}
\hline $\begin{array}{l}\text { Discourse Operators } \\
\Omega \text { and } \Pi\end{array}$ & $\begin{array}{l}\text { referent (already) exists in } \\
\text { discourse world }\end{array}$ & $\begin{array}{l}\text { referent does not exist in } \\
\text { discourse world (yet) }\end{array}$ \\
\hline $\begin{array}{l}\text { Noun phrase } \\
\text { Predication }\end{array}$ & $\begin{array}{l}\Omega=\text { definite } \\
\Pi=\text { actual (realis) }\end{array}$ & $\begin{array}{l}\Omega=\text { indefinite } \\
\Pi=\text { non-actual (irrealis) }\end{array}$ \\
\hline
\end{tabular}

Figure 3. Discourse operators $\Omega$ and $\Pi$.

The operators 'definite' and 'actual' in the formal representation of the underlying structure signal that the speaker wants to indicate that the referents of these phrases (already) have a place in the world of discourse. Conversely, the operators 'indefinite' and 'non-actual' in the underlying structure are an indication for the addressee that the referents of these phrases do not (yet) have an established or identifiable place in the world of discourse.

In the case of an NP the hearer should interpret the indefiniteness operator as an instruction to introduce a new spatial entity in the world of discourse. The nonactuality operator in the underlying structure of the clause also instructs the addressee to construe a new entity as a discourse referent (in this case: an event), but in addition the non-actuality operator tells the addressee that this event must not be 'grounded' or 'anchored' as a real event in the world of discourse. ${ }^{8}$

So what we see is that 'definite' and 'actual' have a similar function in that they signal that the entities they refer to (spatial entity $\mathrm{X}$, temporal entity $\mathrm{E}$ ) exist, or already exist, in the world of discourse (or that their existence is presupposed). Their negative counterparts 'indefinite' and 'non-actual', on the other hand, have in common that the entities they refer to $(\mathrm{X}, \mathrm{E})$ do not exist, 
or do not exist yet, in the world of discourse as identifiable or actual ('anchored') entities. This is captured in the following (incomplete) representations of the noun phrase and the clause/predication (T and $\Sigma$ stand for LEXICAL discourse modifiers in the NP and in the clause, which will remain undiscussed here; again, for a detailed discussion of parallels between NPs and clauses I refer to Rijkhoff 2002: Chapter 7):

(24) noun phrase:

$\left\{\left[\Omega \mathrm{X}_{\mathrm{i}}:\right.\right.$ [descriptive part: $\left.\left.\mathrm{x}\right] \mathrm{T}_{\mathrm{i}}\left(\mathrm{X}_{\mathrm{i}}\right)\right\}$

(25) predication:

$\left\{\left[\Pi \mathrm{E}_{\mathrm{i}}:\right.\right.$ [descriptive part: e] $\left.\Sigma_{\mathrm{i}}\left(\mathrm{E}_{\mathrm{i}}\right)\right\}$

The idea that at some abstract level of representation discourse operators $\Omega$ (in the NP) and $\Pi$ (in the clause) essentially express the same notion (something like: determined or undetermined existence in the shared world of discourse of Speaker and Addressee) is confirmed by the fact that in certain languages the same form is used in the NP and in the clause. In Jakaltek, for example, both the exhortative mood and non-specificity are expressed by the suffix $-o j$, “[...] the general suffix of irrealis [...]" (Craig 1977:93):

Jakaltek (Craig 1977:93)

(26) Way-oj ab naj

sleep-OJ EXH CLF/he

'Would that he sleep!'

X-Ø-'oc heb ix say-a' hun-uj munlabel

ASP-ABS.3-start PL woman look.for-FUT a-OJ pot

'The women started looking for a pot'

In (26) - oj is suffixed to the intransitive verb in the exhortative mood, in (27) it marks the referent of the term phrase as non-specific (cf. also Baker and Travis 1997). As with the descriptive layers, we can also find lexical expressions of the same notion in the NP and in the clause.

We can draw further parallels between NPs and clauses and point out that nominal subcategories specify different Seinsarten ("modes of being"; e.g. MAss or COLLECTIVE - see section 2.4) just like verbs can be characterized in terms of their Aktionsart ("mode of action"; i.e. achievement, state, activity/process, or accomplishments). Apart from lexico-semantic parallels, there are also quite a few morpho-syntactic phenomena to suggest that NPs and clauses can be analyzed in a similar fashion, or (to put it in more neutral terms) that there are interesting structural relationships between NPs and clauses. For example, we find that the order of grammatical and lexical expressions of the various modifier categories have a strong tendency to iconically reflect scope differences 
in the underlying semantic structure (cf. Bybee 1985 on the relative order of aspect, tense, and mood markers in the world's languages; Greenberg 1966, Hawkins 1983 and Rijkhoff 2002 for typological studies on the order of demonstrative, numeral and adjective in the NP).

Diachronic developments also seem to confirm the hypothesis that there are both semantic and morpho-syntactic parallels between NPs and clauses. For example, Gildea (1993) has shown how over time demonstrative pronouns may turn into tense markers (both are represented in the location layer) and Von Garnier already showed in 1909 that collective markers can turn into markers of perfectivity (both occur in the quality layer). Finally, some striking parallels between clauses and NPs in Rapanui (Easter Island) are discussed in Du Feu (1987, 1989, 1996).

\section{Conclusion}

I hope to have demonstrated that grammatical theorizing and linguistic typologizing must go hand in hand and that an approach that integrates the two branches is very rewarding for both linguistic disciplines.

From a theoretical perspective, it would have been impossible to come up with the layered model of the noun phrase without the data that were discovered in the typological investigation. This holds in particular for the nominal aspect markers $\left(\omega_{1}\right)$ and lexical expressions of cardinality $\left(\tau_{2 \mathrm{a}}\right)$, which can only be found in a sample that includes languages from many different families and geographic areas. ${ }^{9}$ On the other hand, it is unlikely that nominal aspect markers could have been discovered without the idea that (to some extent and at some level of abstraction) NPs and clauses share the same underlying semantic structure.

Note finally, that some of the results discussed here have found their way into other theories of grammar besides FG (see Van Valin and LaPolla 1997:56f) as well as descriptive studies (see e.g. Szakos 1994 on Tsou; Schroeder 1999 on Turkish). The sampling method has been used in several typological investigations (e.g. Haspelmath 1997), including some of the studies that were part of the EuroTyp project (Siewierska 1997; van der Auwera 1998). 


\section{Notes}

1. Abbreviations: $1=$ first person, $3=$ third person, $A=$ adjective, $\mathrm{ABS}=$ absolutive, $\mathrm{ASP}=$ aspect, $\mathrm{CLF}=$ classifier, $\mathrm{DEM}=$ demonstrative, $\mathrm{DV}=$ diversity value, $\mathrm{EXH}=$ exhortative, $\mathrm{FG}=$ Dik's Functional Grammar, FUT = future, $\mathrm{GEN}=$ genitive, $\mathrm{L}=$ layer, $\mathrm{M}=$ masculine, $\mathrm{NP}=$ noun phrase, $\mathrm{PERF}=$ perfective, $\mathrm{PL}=$ plural, POss $=$ possessor $\mathrm{NP}, \mathrm{PRT}=$ participle, $\mathrm{RCM}=$ relative clause marker, Rel.cl. $=$ relative clause, $\mathrm{SG}=$ singular.

2. But note that some of my earlier proposals concerning the layered approach to NP structure have been incorporated in Dik (1997); see also Hengeveld (forthcoming).

3. It may be useful to point out here that the direct referent of an NP is not an object in the real world, but rather a mental construct that is created, stored, and retrieved in the minds of the speech participants. This explains why we often find certain discrepancies between (linguistic) properties of discourse referents and (ontological) properties of their real-world counterparts (or Sein-correlates), if they exist. This holds especially true with respect to the features Shape and Homogeneity.

In my classification of nouns, I have tried to use names which say something about the semantics of each nominal subcategory. Note furthermore that, since this is a linguistic and not an ontological classification, there is in principle no direct relationship between noun type and (real world) entity type. This explains, of course, why members of different nominal subcategories (Seinsarten) can be used to refer with the same thing in the extra-linguistic world. For example, whereas the real-world entity 'table' is a discrete physical object, the referent of a NP headed by the equivalent of the noun 'table' in Language L may be (depending on the nominal subcategory employed by speakers of Language L): a general entity, a sort entity, a set entity, or a singular object entity (see also below).

4. I am only considering number marking as an inflectional category of the noun. This excludes languages such as Bambara (Brauner 1974:26-28; Kastenholz 1989:21), in which the number morpheme is a phrase final enclitical element, so that it is properly speaking not the noun but rather the NP that is marked for number (Rijkhoff 2002:31-32).

5. According to Ratliff (1991:696) cov has a collective meaning and most probably derives from coy ${ }^{51}$ 'bunches or clusters of fruit' (superscript 51 indicates tone marks).

6. See Searle (1969: Chapter 2); cf. also Mackenzie (1987), Dik (1997:127f), Hengeveld (forthcoming) on referring and predicating as part of performing an illocutionary act.

7. There is no one-to-one relationship between form and function, especially in the case of lexical modifiers $(\tau)$. For example, quality, quantity, and location satellites can all be expressed in the form of a relative clause (quality: 'the man who is rich'; quantity (in quasiEnglish): 'the children who were four'; location (in time/space): 'the woman I met on the train this morning').

Notice that grammatical and lexical modifier categories (symbolized by the Greek characters $\omega$ and $\tau$ ) are distributed over domains that correspond to three of Aristotle's basic categories: quality, quantity, and location. Modifiers are ordered relative to the noun phrase in terms of semantic scope. This means that modifier categories that only relate to the noun are represented immediately before or after the noun, and that modifiers with a wider scope occur further away from the noun. By convention, the structure is written from left to right, 
with operators (grammatical categories) on the left side of the noun and satellites (lexical modifier categories) on the right side of the noun.

8. This asymmetry may point to a fundamental difference between first and second order (spatial and temporal) entities (see also Harder 1996:280). Whereas there are numerous ways that a spatial entity can be definite, there is basically one way for an event to be actual: because it (has) occurred or is occurring. Similarly: whereas there is basically one way for a spatial entity to be indefinite, there are numerous ways that a temporal entity (an event) can be less than completely actual (cf. also Chung and Timberlake 1985:241).

9. This statement reflects a Eurocentric perspective, of course. In my place, a non-Western linguist might have spent some time searching for a language that employs definite articles or inflectional tense marking.

\section{References}

Andrzejewski, B.W. (1960) The categories of number in noun forms in the Borana dialect of Galla. Africa 30: 62-75.

Baker, M. and L. Travis (1997) Mood as verbal definiteness in a "tenseless" language. Natural Language Semantics 5: 213-269.

Bisang, W. (1996) Areal typology and grammaticalization: processes of grammaticalization based on nouns and verbs in East and mainland South East Asian languages. Studies in Language 20.3: 519-597.

Brauner, S. (1974) Lehrbuch des Bambara. Leipzig: Enzyklopädie.

Bybee, J.L. (1985) Morphology: A study of the relation between meaning and form (Typological Studies in Language, 9.) Amsterdam: Benjamins.

Christie, J. J. (1970) Locative, possessive and existential in Swahili. Foundations of Language 6: $166-177$.

Chung, S. and A. Timberlake (1985) Tense, aspect, and mood. In T. Shopen (ed.) Language typology and syntactic description: Volume III: Grammatical categories and the lexicon. Cambridge: Cambridge University Press. 202-258.

Clark, E. V. (1978) Locationals: existential, locative, and possessive constructions. In J.H. Greenberg, Ch.A. Ferguson, and E. A. Moravcsik (eds.) Universals of human language: Vol. 4: Syntax. Stanford: Stanford University Press. 85-126.

Craig, C. (1977) The structure of Jacaltec. Austin: University of Texas Press.

Craig, C. (1992) Classifiers in a functional perspective. In M. Fortescue, P. Harder, and L. Kristoffersen (eds.) Layered structure and reference in Functional Grammar. Amsterdam: Benjamins. 277-301.

Croft, W. (2002) On being a student of Joseph Greenberg. Linguistic Typology 6.1: 3-8 [Special issue: Remembering Joseph H. Greenberg (1915-2001)].

Dik, S.C. (1997) The theory of Functional Grammar. Part 1: The structure of the clause. 2nd revised edition, edited by K. Hengeveld. Berlin: Mouton.

Du Feu, V.M. (1987) The determinants of the noun in Rapanui. Journal of the Polynesian Society 96: 473-495. 
Du Feu, V.M. (1989) Verbal parameters expressed in the NP in Rapanui. Paper read at the Colloquium on NP Structure, University of Manchester, September 1989.

Du Feu, V.M. (1996) Rapanui. London: Routledge.

Foley, W.A. (1997) Anthropological linguistics: An introduction. Oxford: Blackwell.

Gildea, S. (1993) The development of tense markers from demonstrative pronouns in Panare (Cariban). Studies in Language 17.1: 53-73.

Greenberg, J.H. (1966) Some universals of grammar with particular reference to the order of meaningful elements. In J.H. Greenberg (ed.) Universals of language. 2nd ed. Cambridge: MIT. 73-113.

Grimes, B.F. (ed.) (1997) Ethnologue: Languages of the world. 13th ed. Dallas: Summer Institute of Linguistics.

Grinevald, C. (2000) A morphosyntactic typology of classifiers. In G. Senft (ed.) Systems of nominal classification. Cambridge: Cambridge University Press. 50-92.

Harder, P. (1996) Functional semantics: A theory of meaning, structure and tense in English. Berlin: Mouton.

Harriehausen, B. (1990) Hmong Njua: Syntaktische Analyse einer gesprochenen Sprache mithilfe datenverarbeitungstechnischer Mittel und sprachvergleichende Beschreibung des südostasiatischen Sprachraumes (Linguistische Arbeiten, 245.) Tübingen: Niemeyer.

Harris, A.C. (1981) Georgian syntax: A study in relational grammar (Cambridge Studies in Linguistics, 33.) Cambridge: Cambridge University Press.

Haspelmath, M. (1997) Indefinite Pronouns (Oxford Studies in Typology and Linguistic Theory) Oxford: Oxford University Press.

Hawkins, J. A. (1983) Word order universals: Quantitative analyses of linguistic structure. New York: Academic Press.

Heine, B. (1997) Possession: Cognitive sources, forces, and grammatizalization (Cambridge Studies in Linguistics, 83.) Cambridge: Cambridge University Press.

Hengeveld, K. (1989) Layers and operators in Functional Grammar. Journal of Linguistics 25: 127-157.

Hengeveld, K. (1990) The hierarchical structure of utterances. In J. Nuyts, A. M. Bolkestein, and C. Vet (eds.) Layers and levels of representation in language theory: A functional view. Amsterdam: Benjamins. 1-23.

Hengeveld, K. (forthcoming) Epilogue. In J.L. Mackenzie and M. A. Gómez González (eds.) A new architecture for Functional Grammar (Functional Grammar Series, 24.) Berlin: Mouton.

Hundius, H. and U. Kölver (1983) Syntax and semantics of numeral classifiers in Thai. Studies in Language 7.2: 164-214.

Kastenholz, R. (1989) Grundkurs Bambara (Manding) mit Texten. Köln: Köppe.

Kutsch Lojenga, C. (1994) Ngiti: A Central-Sudanic language of Zaire. Köln: Köppe.

Li, Ch.N. and S.A. Thompson (1981 [1989]) Mandarin Chinese: A functional reference grammar. Berkeley: University of California Press.

Lucy, J. A. (1992) Grammatical categories and cognition: A case study of the linguistic relativity hypothesis (Studies in the Social and Cultural Foundations of Language, 13.) Cambridge: Cambridge University Press.

Lyons, J. (1967) A note on possessive, existential and locative sentences. Foundations of Language 3: 390-396. 
Lyons, J. (1977) Semantics. 2 vols. Cambridge: Cambridge University Press.

Mackenzie, J.L. (1987) The representation of nominal predicates in the fund. Working Papers in Functional Grammar 25. Amsterdam: Dept. of Linguistics, University of Amsterdam. Mithun, M. (1988) Lexical categories and the evolution of number marking. In M. Hammond and M. Noonan (eds.) Theoretical morphology: Approaches in modern linguistics. New York: Academic Press. 211-234.

Noonan, M. P. (1992) A grammar of Lango (Mouton Grammar Library, 7.) Berlin: Mouton. Norman, Jerry. 1988. Chinese. Cambridge: Cambridge University Press.

Ratliff, M. (1991) Cov, the underspecified noun, and syntactic flexibility in Hmong. Journal of the American Oriental Society 111.4: 694-703.

Rijkhoff, J. (1991) Nominal aspect. Journal of Semantics 8: 291-309.

Rijkhoff, J. (1993) 'Number' disagreement. In A. Crochetière et al. (eds.) Proceedings of the XVth International Congress of Linguists. Sainte-Foy, Québec: Presses de l'Université Laval. 274-276.

Rijkhoff, J. (2000) When can a language have adjectives? An implicational universal. In P. Vogel and B. Comrie (eds.) Approaches to the typology of word classes. Berlin: Mouton de Gruyter. 217-257.

Rijkhoff, J. (2002) The noun phrase (Oxford Studies in Typology and Linguistic Theory) Oxford: Oxford University Press.

Rijkhoff, J. and D. Bakker (1998) Language sampling. Linguistic Typology 2.3: 263-314.

Rijkhoff, J., D. Bakker, K. Hengeveld, and P. Kahrel (1993) A method of language sampling. Studies in Language 17.1: 169-203.

Ruhlen, M. (1987) A guide to the world's languages: Vol. 1: Classification. London: Arnold.

Schachter, P. (1985) Parts-of-speech systems. In T. Shopen (ed.) Language typology and syntactic description: Volume I: Clause structure. Cambridge: Cambridge University Press. 3-61.

Schroeder, Chr. (1999) The Turkish nominal phrase in spoken discourse (Turcologica, 49.) Wiesbaden: Harrassowitz.

Searle, J. (1969) Speech acts: An essay in the philosophy of language. Cambridge: Cambridge University Press.

Siewierska, A. (ed.) (1997) Constituent order in the languages of Europe (Empirical Approaches to Language Typology/Eurotyp, 20-1.) Berlin: Mouton.

Stroomer, H. (1987) A comparative study of three southern Oromo dialects in Kenya: Phonology, morphology and vocabulary (Cushitic Language Studies, 6.) Hamburg: Buske.

Szakos, J. (1994) Die Sprache der Cou: Untersuchungen zur Synchronie einer austronesischen Sprache auf Taiwan. Dissertation, Rheinische Friedrich-Wilhelms-Universität.

van Baarda, M.J. (1908) Leiddraad bij het bestuderen van ' $t$ Galela'sch dialekt, op het eiland Halmaheira [Manual for the study of the Galela dialect, on the island of Halmahera]. The Hague: Nijhoff.

van der Auwera, J. (ed.) (1998) Adverbial constructions in the languages of Europe (Empirical Approaches to Language Typology/Eurotyp, 20-3.) Berlin: Mouton.

Van Valin, R.D., Jr. and R.J. LaPolla (1997) Syntax: Structure, meaning and function. Cambridge: Cambridge University Press.

Voegelin, Ch.F. and F.M. Voegelin (1977) Classification and index of the world's languages. New York: Elsevier. 
von Garnier (geb. Moewes), K. (1909) com-als perfektierendes Praefix bei Plautus, sam- im Rigveda, cuv- bei Homer. Indogermanische Forschungen 25: 86-109.

\section{Author's address}

Jan Rijkhoff

Department of Linguistics

Aarhus University

Jens Chr. Skous Vej 7

DK-8000 Aarhus C

Denmark

linjr@hum.au.dk 